\title{
Studies on the Intracellular Haemagglutinin Component of Fowl Plague Virus and other Myxoviruses
}

\author{
By JUNE D. ALMEIDA \\ Department of Medical Microbiology, St Thomas's Hospital \\ Medical School, London, S.E. 1 \\ F. HIMMELWEIT AND A. ISAACS \\ National Institute for Medical Research, Mill Hill, London, N.W. 7
}

(Received 24, March 1966)

\section{SUMMARY}

In contrast to other members of the influenza virus group, a strain of fowl plague virus produced large amounts of intracellular haemagglutinin in the chorioallantoic membranes of infected chick embryos. The titres of intracellular haemagglutinin obtained with the fowl plague virus were 400-2000-fold higher than those of the human influenza viruses tested. The fowl plague virus also differed from the human influenza viruses in being capable of growing through the chorioallantoic membrane when inoculated by the chorionic route. The only other myxovirus so far discovered that elicited a high intracellular haemagglutinin titre was Newcastle disease virus, although this type of virus is neither serologically nor morphologically related to the influenza viruses.

Electron microscopic investigations of membrane specimens from embryos infected with fowl plague virus showed the presence of a large number of structures, ranging in size from $300 \AA$ to more than $7000 \AA$, with a surface configuration indistinguishable from that of the envelope component of typical particles. Similar structures were found very rarely in specimens of membranes infected with the human influenza viruses.

\section{INTRODUCTION}

During a study of the rate at which different factors appear in the course of virus multiplication, high titres of viral haemagglutinin were found in chorioallantoic membranes of chick embryos infected with fowl plague virus. The present report describes comparative investigations with other myxoviruses and efforts, by electron microscopy, to characterize the fowl plague haemagglutinin present in the chorioallantoic membrane.

\section{METHODS}

Virus strains used were the 'Dutch' strain of fowl plague virus, the PR 8 strain of influenza virus $A$, the $B /$ England/939/59 strain of influenza virus $B$, and an undesignated, but characterized, strain of Newcastle disease virus kept at the National Institute for Medical Research. The strains were propagated by allantoic infection of 10-day-old chick embryos incubated at $37^{\circ}$, or other chosen temperatures. In addition, the fowl plague virus was inoculated by the chorionic route. 
Infectivity assays were made by plaque counts in monolayers of chick embryo fibroblasts (Dulbecco, 1952).

Haemagglutination $(\boldsymbol{H A})$ titrations. Each infected membrane was washed in three changes of saline, suspended in $1 \mathrm{ml}$. saline/membrane, frozen and thawed once, ground in a glass homogenizer and centrifuged for $10 \mathrm{~min}$. at $1000 \mathrm{rev} . / \mathrm{min}$. Supernatant fluids and infective allantoic fluids were titrated in plastic trays in accordance with the technique described by the WHO Expert Committee on Influenza (1953). Haemagglutination inhibition tests with immune sera were also done as recommended by the Committee.

Electron microscopy. Specimens were prepared from infected allantoic fluids and membranes. For specimens from allantoic fluid, $5 \mathrm{ml}$. of fluid was cleared of debris by centrifuging at $2000 \mathrm{rev} . / \mathrm{min}$. for $10 \mathrm{~min}$. The supernatant fluid was spun at $144,000 \mathrm{~g}$ for half an hour and the pellet suspended in $0.1 \mathrm{ml}$. distilled water. A drop of this suspension was first negatively stained by mixing with an equal quantity of $3 \%$ phosphotungstic acid previously adjusted to $\mathrm{pH} 6$ (Brenner \& Horne, 1959), and then placed on a carbon-formvar-coated grid. Excess fluid was withdrawn from the grid with filter paper and the specimen immediately examined with a Philips 200 Electron Microscope. Specimens from chorioallantoic membrane, since it was desired to view the cell constituents of the membrane with as little alteration as possible, were examined in the electron microscope after a minimum of preparatory procedure. Small portions of freshly harvested membrane were rinsed in phosphate-buffered saline (PBS) and then transferred to the well of a hollow ground slide. After adding $\mathbf{0 \cdot 2} \mathrm{ml}$. distilled water, the fluid was agitated with a Pasteur pipette. This served to disrupt the cells and a suspension of cell fragments was obtained. This suspension was then negatively stained in the same manner as the suspension of the allantoic fluid pellet.

\section{RESULTS}

\section{Haemagglutinin}

Twenty-four hr after inoculating chick embryos by the allantoic route with $10^{3}-10^{4}$ plaque forming units (p.f.u.) of fowl plague virus, the viral haemagglutinin in the allantoic fluid had reached almost its peak titre. The intracellular haemagglutinin of membranes, however, continued to increase steeply to a very high maximum titre $48 \mathrm{hr}$ after infection (Fig. 1). Further increase was not observed since this virus was lethal for the embryos. The infectivity titres of allantoic fluid and membrane extract were very similar. However, because of the discrepancy between the haemagglutination titres, the p.f.u.: HA ratio of the membrane extract was approximately $1.5 \mathrm{log}$ lower than that of the allantoic fluid. By contrast, the PR 8 strain of influenza A and strain B/England/939/59 viruses gave much lower titres of intracellular haemagglutinin at all periods up to $72 \mathrm{hr}$ after virus inoculation (Table 1). In this respect Newcastle disease virus of fowls (NDV) resembles fowl plague virus, particularly when grown at $42^{\circ} . \mathrm{NDV}$ grown at $33^{\circ}$ had a slightly lower titre than NDV grown at $42^{\circ}$.

The haemagglutinin that appears within cells infected by fowl plague virus is serologically specific, as is that produced by NDV. In fact, the intracellular haemagglutinin of NDV was inhibited by immune serum to a fourfold higher titre than the 
haemagglutinin of the allantoic fluid, but was not inhibited by antiserum to fowl plague virus. The intracellular haemagglutinins of fowl plague and of NDV also showed a very rapid elution from chick red cells, so that within 1-2 hr of reading a pattern test at room temperature, the haemagglutination pattern had disappeared.

Further information on the production of intracellular fowl plague haemagglutinin was, following a suggestion by $\mathrm{Dr}$ A. Harboe, obtained by infecting the chorionic cells of the chorioallantoic membrane with the virus. In contrast to

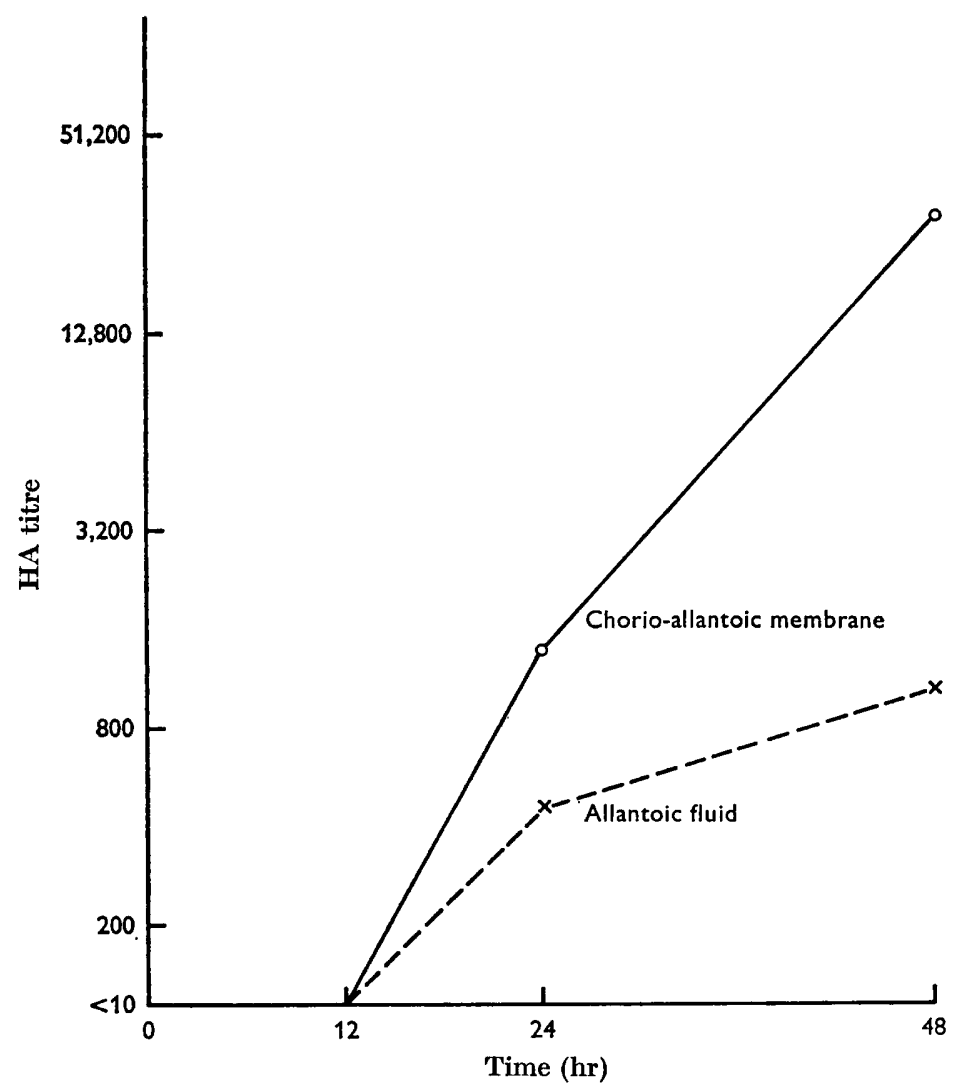

Fig. 1. Haemagglutinin titres of fowl plague virus in the chorioallantoic membrane and allantoic fluid of 10-day-old eggs infected allantoically. The ordinate shows the haemagglutinin titre with $0.5 \%$ chick red cells in a pattern test. Membranes were suspended in $1 \mathrm{ml}$. saline, and the haemagglutinin was extracted by freezing and thawing once, followed by grinding in a glass homogenizer.

human influenza viruses, which show only a single cycle of multiplication when inoculated on the chorion (Fulton \& Isaacs, 1953), fowl plague virus, after inoculation on the chorion spread to, and infected the allantoic cells. Forty-eight hr after infection, membranes yielded high haemagglutinin titres comparable with those obtained from allantoically inoculated eggs; in addition, haemagglutinin was present in the allantoic fluids (Table 2). The titres of haemagglutinin in the allantoic fluids of eggs inoculated on the chorion were variable, but nearly as high as those of eggs inoculated by the allantoic route. 
Intracellular haemagglutinin extracted from membranes infected with fowl plague virus, and infective particles in allantoic fluid were treated for 30 sec. in an ultrasonic bath (Burndept Ltd.). The viral haemagglutinin in the allantoic fluid showed no change in titre. The intracellular haemagglutinin recovered from the deposit after centrifuging the membrane homogenate at $500 \mathrm{rev} . / \mathrm{min}$. for $10 \mathrm{~min}$., however, showed a 4 to 6 -fold increase in titre, while the haemagglutinating activity of the supernatant increased only by $50 \%$.

Table 1. Haemagglutinin titres of allantoic fluid and chorioallantoic membranes at different times after infection with myxoviruses

$\begin{array}{lcccc}\text { Virus } & \begin{array}{c}\text { Temperature } \\ \left(^{\circ}\right)\end{array} & \begin{array}{c}\text { Period of } \\ \text { incubation } \\ (\mathrm{hr})\end{array} & \overbrace{\begin{array}{c}\text { Allantoic } \\ \text { fluid }\end{array}}^{\text {Haemagglutinin titres of }} & \begin{array}{c}\text { Chorioallantoic } \\ \text { membrane }\end{array} \\ \text { PR8 } & 37 & 19 & 8 & - \\ & & 48 & 300 & 16 \\ \text { B/Eng./939/59 } & 37 & 19 & 320 & - \\ & & 48 & 1,600 & 80 \\ \text { NDV } & & 72 & 1,280 & 2 \\ & 33 & 48 & 600 & 1,200 \\ \text { Fowl plague } & 42 & 48 & 600 & 4,800 \\ & 37 & 48 & 1,000 & 32,000\end{array}$

Table 2. Haemagglutinin titres of allantoic fluids of embryos inoculated with forl plague virus by the allantoic or chorionic route

$\begin{array}{cccc}\text { Egg no. } & \begin{array}{c}\text { Allantoic } \\ \text { route }\end{array} & \text { Egg no. } & \begin{array}{c}\text { Chorionic } \\ \text { route }\end{array} \\ 1 & 1920 & 6 & 160 \\ 2 & 10 & 7 & 320 \\ 3 & 1920 & 8 & 480 \\ 4 & 1280 & 9 & 1280 \\ 5 & 960 & 10 & 120\end{array}$

\section{Electron microscopy}

The results of electron microscopic examination of specimens prepared from the allantoic fluid and the chorioallantoic membrane of chick embryos infected with fowl plague virus are illustrated in Pl. 1, figs. 1-2 and Pl. 2, figs. 3-5. The specimens originating from the allantoic fluid (fig. 1) contained large numbers of pleomorphic fowl plague virus particles, $700-1000 \AA$ in diameter. In addition, filamentous forms were seen, similar to those found with other influenza viruses. In chorioallantoic membrane preparations, typical viral forms were few and, at times, difficult to find. All membrane specimens (figs. 2-5) contained, however, large numbers of structures exhibiting the fringed surface seen with negatively stained influenza viruses. These structures differed from typical particles in their greater variation of shape and the wider size range from $300 \AA$ to more than $7000 \AA$. The smaller structures resembled rosettes (fig. 4) and bottle-brush forms (fig. 5). Within the size range of typical particles, many forms were seen which, because of their staining characteristics appeared to be merely viral envelopes. Instead of the amorphous, electron trans- 
parent appearance usually presented by the central area of influenza virus particles (fig. 1), the central area of these forms was such that the end-on orientated surface projections were well resolved. A similar effect was also seen with the larger fringed structures (figs. 2 and 3 ).

In specimens prepared from chorioallantoic membranes infected with the PR8 strain of influenza virus $A$, and with the $B /$ England/939/59 influenza virus strain a similarly small number of typical virus particles was present as for fowl plague, but the virus-associated structures were present in such small numbers that they could be found only with difficulty.

\section{DISCUSSION}

The comparative investigations on the presence of haemagglutinin in infected chorioallantoic membranes show a distinct difference between the behaviour of the human influenza viruses tested and that of the fowl plague virus and of NDV. Membranes infected with the fowl plague virus contained, for example, 400-2000 times more haemagglutinin than membranes infected with the human influenza viruses. The avian influenza virus and the NDV may have produced large amounts of haemagglutinin because they found in the cells of the chick embryo-their natural host-a more suitable milieu than did the influenza viruses of human origin. This is supported by the observation that when inoculated by the chorionic route, the fowl plague virus, in contrast to human influenza viruses (Fulton \& Isaacs, 1953), was capable of growing through the chorioallantoic membrane.

The very high haemagglutination titres of the extracts of the chorioallantoic membrane infected with fowl virus plague are paralleled by the electron microscopical finding of large numbers of structures with a fringed surface. Many of these structures are morphologically similar to the incomplete fowl plague virus particles described and depicted by Waterson, Rott \& Schäfer (1961). The small rosettes and bottle-brush forms present in our preparations are very similar to the forms seen by these authors and by Waterson (personal communication) in ether-treated preparations of standard and incomplete fowl plague virus recovered from infected allantoic fluids. Inasmuch as haemagglutinating properties have been ascribed to structural features of the viral envelope of many myxoviruses (cf. Hoyle, Horne \& Waterson, 1961; Rott \& Schäfer, 1961) it is likely that the fringed structures illustrated in figs. $2-5$ bear the intracellular haemagglutinin. The results of the ultrasonic treatment of fractions of the homogenate of fowl plague-infected membrane makes it likely that the observed increase in haemagglutinating activity is primarily due to a fragmentation of the larger structures. The presence of the small rosettes and bottlebrush forms in our membrane specimens is of interest because, hitherto, such structures have been seen only in preparations of influenza viruses treated with a solvent, whereas in membranes infected with fowl plague virus they appear to occur naturally.

We are greatly indebted to Professor A. P. Waterson, Dr H. G. Pereira and Dr R. C. Valentine for their helpful criticism of the manuscript and wish to thank Mrs V. Clay-Peters and Miss M. Dorr for able technical assistance. 


\section{REFERENCES}

Brenner, S. \& Horne, R. W. (1959). A negative staining technique for high resolution electron microscopy of viruses. Biochim. biophys. Acta 34, 103.

DuLBecco, R. (1952). Production of plaques in monolayer tissue cultures by single particles of an animal virus. Proc. natn. Acad. Sci., U.S.A. 38, 747.

Fulton, F. \& Isaacs, A. (1953). Influenza virus multiplication in the chick chorioallantoic membrane. J. gen. Microbiol. 9, 119.

Hoyle, L., Horne, R. W. \& Waterson, A. P. (1961). The structure and composition of the myxoviruses. II. Components released from the influenza virus particle by ether. Virology 13, 387.

RotT, R. \& SCHÄFER, W. (1961). Fine structure of subunits isolated from Newcastle Disease Virus (NDV). Virology 14, 298.

Waterson, A. P., Rott, R. \& Schäfer, W. (1961). The structure of fowl plague virus and virus N. Z. Naturf. $16 b, 154$.

W.H.O. Expert Committee on Influenza (1953). Wld Hith Org. techn. Rep. Ser. 64, 32.

\section{EXPLANATION OF PLATES}

\section{Plate 1}

Fig. 1. Group of typical fowl plague particles obtained from allantoic fluid. Both rounded and elongated forms can be seen. Negatively stained with PTA $(\times 210,000)$.

Fig. 2. Very large structure, probably membranous in nature, with fringed surface and dense, unstructured marginal areas. The vertically orientated projections in central parts of the surface are resolved. Cell spread preparation of chorioallantoic membrane infected with fowl plague virus. Negatively stained with PTA $(\times 210,000)$.

\section{Plate 2}

Fig. 3. Large balloon-shaped structure with round or kidney shaped dense areas in the periphery. In the central area, the vertically orientated projections of the fringed surface component are resolved. Origin of cell spread preparation as described in legend to fig. 2. Negatively stained with PTA $(\times 450,000)$.

Fig. 4. Collection of rosettes in cell spread preparation of chorioallantoic membrane infected with fowl plague virus. Negatively stained with PTA $(\times 450,000)$.

Fig. 5. Several bottle-brush forms present in cell spread preparation of fowl plague-infected membrane. Negatively stained with PTA $(\times 450,000)$. 

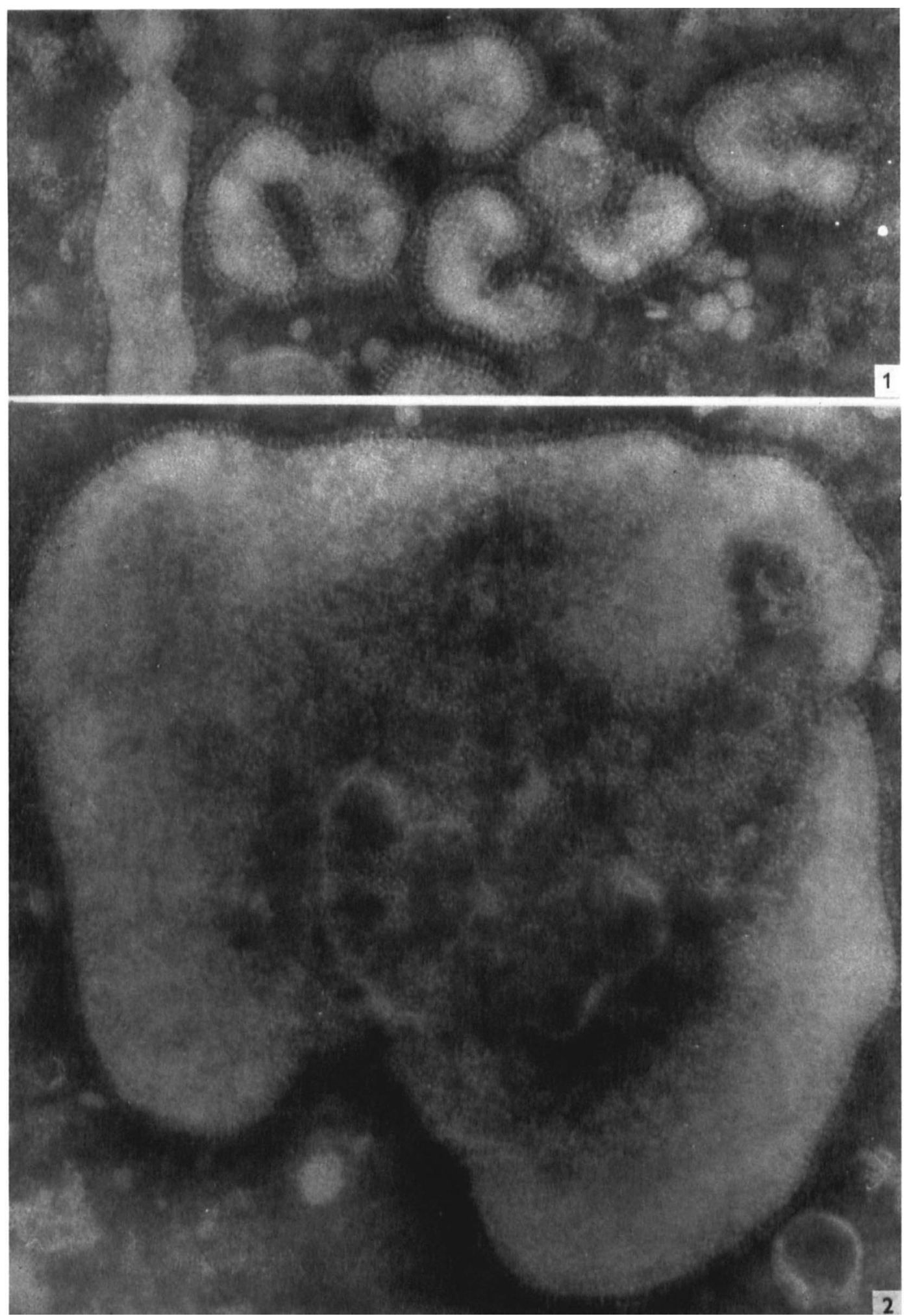

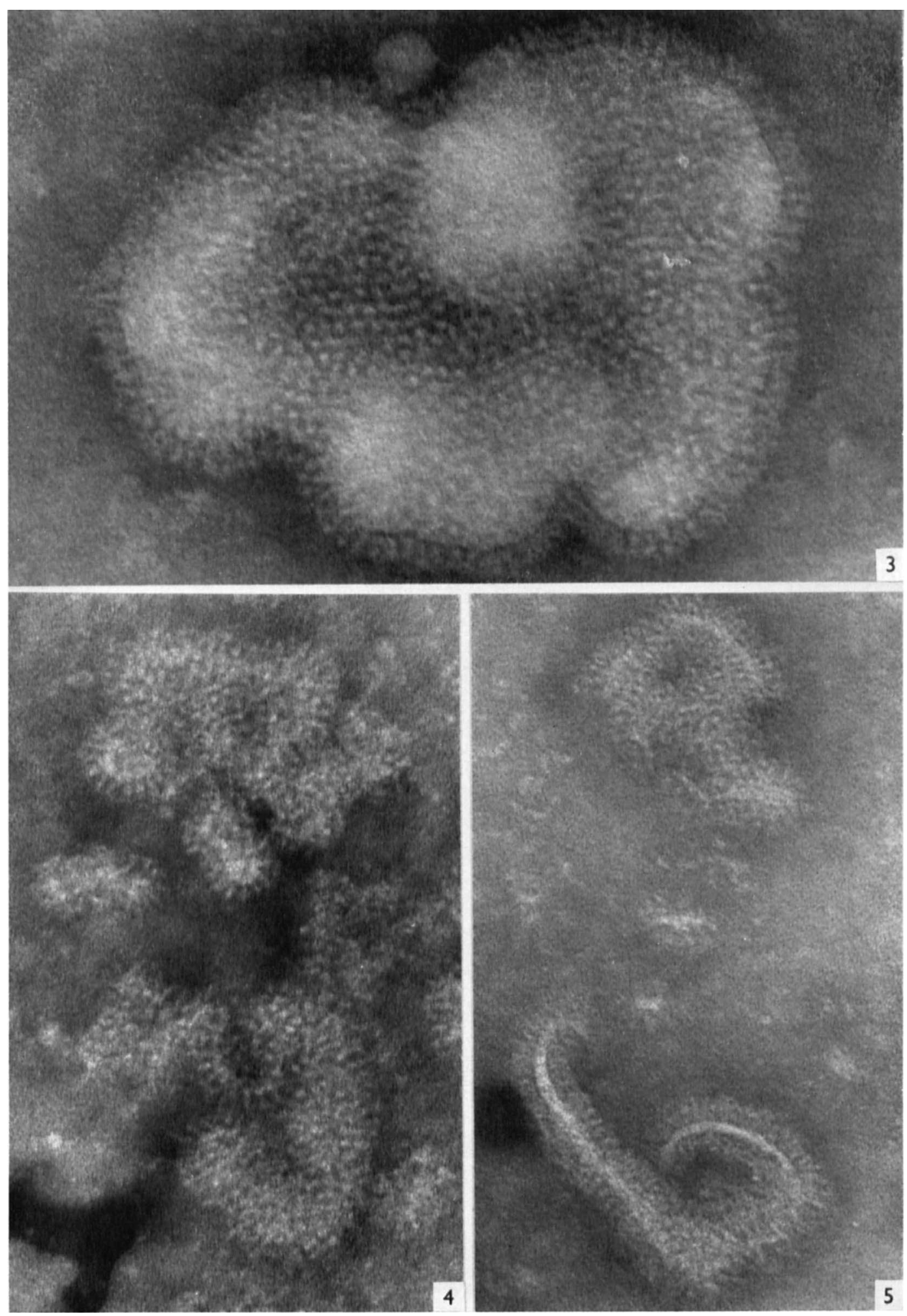

J. D. ALMEIDA, F. HIMMELWEIT AND A. ISAACS 